\title{
A human pluripotent stem cell platform for assessing developmental neural toxicity screening
}

\author{
Zhonggang Hou', Jue Zhang', Michael P Schwartz², Ron Stewart', C David Page ${ }^{3}$, William L Murphy²,4 \\ and James A Thomson ${ }^{* 1,5,6}$
}

\begin{abstract}
A lack of affordable and effective testing and screening procedures mean surprisingly little is known about the health hazards of many of the tens of thousands of chemicals in use in the world today. The recent rise in the number of children affected by neurological disorders such as autism has stirred valuable debate about the role chemicals play in our daily life, highlighting the need for improved methods of assessing chemicals for developmental neural toxicity. Current methods of testing chemicals for developmental neural toxicity include animal testing with rats or mice and in vitro testing using cultured primary cells or cell lines. Here, we review the current state of neural toxicity screening, analyze the limitations of these methods and, under the National Institutes of Health's new Microphysiological Systems initiative, describe a human pluripotent stem cell-based platform for developmental neural toxicity screens.

Keywords: developmental neural toxicity, human pluripotent stem cells, machine learning, threedimensional hydrogel culture, Microphysiological Systems initiative
\end{abstract}

\section{Introduction}

There is an urgent need for effective, predictive neural developmental toxicity screens both for drug candidates and for chemicals intentionally (for example, cosmetics) and unintentionally (for example, pesticides) coming into contact with the human body [1-3]. The European Union's 2006 Registration, Evaluation, Authorization, and Restriction of Chemicals regulations aim to assess the toxicity of all chemicals sold in Europe in quantities of

${ }^{*}$ Correspondence: jthomson@morgridgeinstitute.org

'Morgridge Institute for Research, 330 N Orchard Street, Madison, WI 53715, USA Full list of author information is available at the end of the article more than 1 ton per year. As of late 2009, 143,835 chemicals were listed as meeting this threshold [4]. However, the United States has no database of all chemicals in commerce and thus actual numbers are unknown. In addition, of the 3,000 chemicals categorized as high production in the United States (that is, $>1$ million pounds per year), only $7 \%$ have been comprehensively evaluated for toxicity as of 1998, largely due to the high cost of multigeneration animal studies and the lack of alternative testing methods [5].

In the United States, the US Environmental Protection Agency's ToxCast and v-Embryo projects, and the US Environmental Protection Agency/National Institutes of Health (NIH)/US Food and Drug Administration's collaborative Tox21 project all seek to develop more rapid chemical and drug testing methods [6,7]. Yet it remains imperative to increase the representation of human cellular differentiation models in these in vitro screening efforts. Under the new NIH Microphysiological Systems initiative, we are developing human predictive neural developmental screens of broad use for pharmaceutical and chemical industries that will complement previous toxicology efforts.

\section{Limitations of current developmental neural toxicity screens}

Current methods of developmental neural toxicity testing fall into two categories with unique limitations: in vivo testing using laboratory animals, and in vitro testing using cultured cells.

Laboratory animals have long been used as human surrogates for testing the neural toxicity of chemicals. The most widely used animal for this purpose is the rat, and then to lesser degrees the mouse, rabbit and dog. In developmental neural toxicity tests, chemical exposure starts early in pregnancy and ends weeks after delivery [8]. The toxic effects of the chemicals are then evaluated by standard neurological testing of the pups and by analysis of histological tissue sections of the pups' neural tissues [8].

Although these studies can be informative, the reported concordance for developmental/reproductive toxicity 
testing between different animal species (typically rat and rabbit) is only about $60 \%$ [3], and there is no evidence that the concordance between either species and human toxicity is any better. A good example of this is the chemical thalidomide, which causes birth defects in humans but has little effect in rats [9]. In addition, because of species-specific differences, subtle cognitive changes and human conditions with no known counterparts in animal behavior (for example, autism) are particularly difficult to model in animals [10]. Finally, the cost of multigeneration animal studies is considerable (>\$1 million/study). Animal testing is projected to account for a staggering 70\% of the European Union's 2006 Registration, Evaluation, Authorization, and Restriction of Chemicals cost of evaluating a new chemical, and to consume an average of 3,200 rats per chemical [4].

Performing chemical screens on in vitro human models is another method of developmental neural toxicity testing. Currently, however, no in vitro human models are in widespread use for assessing developmental neurotoxicity. A few studies have examined the effects of toxins on human fetal-derived neurospheres. Human central nervous system neurospheres of fetal origin include stem cells, neurons, and astrocytes that self-assemble into structures which recapitulate some early neural developmental events [11], providing rare access to the developing human neural system. However, these neurospheres lack microglia and vascular cells and therefore do not represent the entire repertoire of cell-cell interactions comprising the brain. They are also hard to obtain in large quantities, making large-scale chemical screens impractical. Furthermore, individual differences between donors may introduce variations between screenings, potentially complicating downstream data analysis.

Human embryonic stem (ES) cells and induced pluripotent stem (iPS) cells, which have unlimited proliferative potential, provide a more practical option for building in vitro models [12-14]. The efficient derivation of neural cells from human pluripotent stem cells is now possible, paving the way for recent reports of developmental neural toxicity testing on human ES cell-derived neurons [15-18]. However, the number of toxins examined in these studies has been extremely small (typically one to four) and the types of cells included in the screen have been limited $[17,18]$. The value of these model systems to actually predict neural toxicity in wider chemical screens remains to be examined.

\section{An innovative platform for developmental neural toxicity screen}

Under the NIH's Microphysiological Systems initiative, we are building a platform for developmental neural toxicity testing on a physiologically relevant human model.
A combination of stem cell biology, tissue engineering and bioinformatics, this platform is capable of meeting the needs of large-scale chemical toxicity screens (Figure 1).

A central characteristic of our platform is that a remarkable degree of self-assembly, differentiation, and maturation occurs if appropriately specified precursor cells are brought together in the right environment. The most impressive experimental example of self-assembly is the formation of teratomas by ES cells and iPS cells. If allowed sufficient time to develop, these teratomas form well-developed, highly stratified neural structures that closely recapitulate early brain development [19], and form other advanced structures requiring complex inductive interactions between germ layers, including gut, teeth, and hair [12]. The differentiation and selfassembly of polarized cortical tissues, including ventricular, early and late cortical plate, and Cajal-Retzius zones, has also been demonstrated previously from the in vitro culture of ES cell-derived aggregates, a significant finding for our platform [20].

To create these physiologically relevant three-dimensional structures, we embed human ES/iPS cell-derived endothelial cells, pericytes, and primitive macrophages (microglial precursors) into tunable poly(ethylene glycol) hydrogels displaying specific peptide motifs that promote capillary network formation (Figures 1a and 2). We then overlay this mesenchymal layer with neural and glial precursors to mimic in vivo cephalic mesenchyme-neural epithelial interactions, both to promote the formation of the polarized layers of the cerebral cortex and to allow the formation of endothelial networks with blood-brain barrier properties (Figure 1a). Poly(ethylene glycol) hydrogels have found widespread use in three-dimensional cell culture due to their ease of processing and biocompatibility [21]. Cells can be readily encapsulated within these gels using photo-polymerization [22-24] (Figure 2a), providing a simple mechanism to generate hydrogel arrays with well-defined local spots directly amenable to high-throughput screens. A key prerequisite of this approach is a consistent and scalable source of correctly specified precursors. Recent progress in deriving neural, glial, and vascular precursors from human pluripotent stem (ES and iPS) cells [25-29] provides this scalable source for the first time.

The nature of developmental timing poses perhaps the most significant challenge to this project. The timing of human ES/iPS cell differentiation largely recapitulates the timing of normal human fetal development. Although it is possible to set up cultures of differentiating human cells that interact for 9 months or longer, such culture systems would not be practical for high-throughput drug screens. Our strategy, then, is to predifferentiate the early precursors of the components of the cerebral cortex in 
(a)

(b)
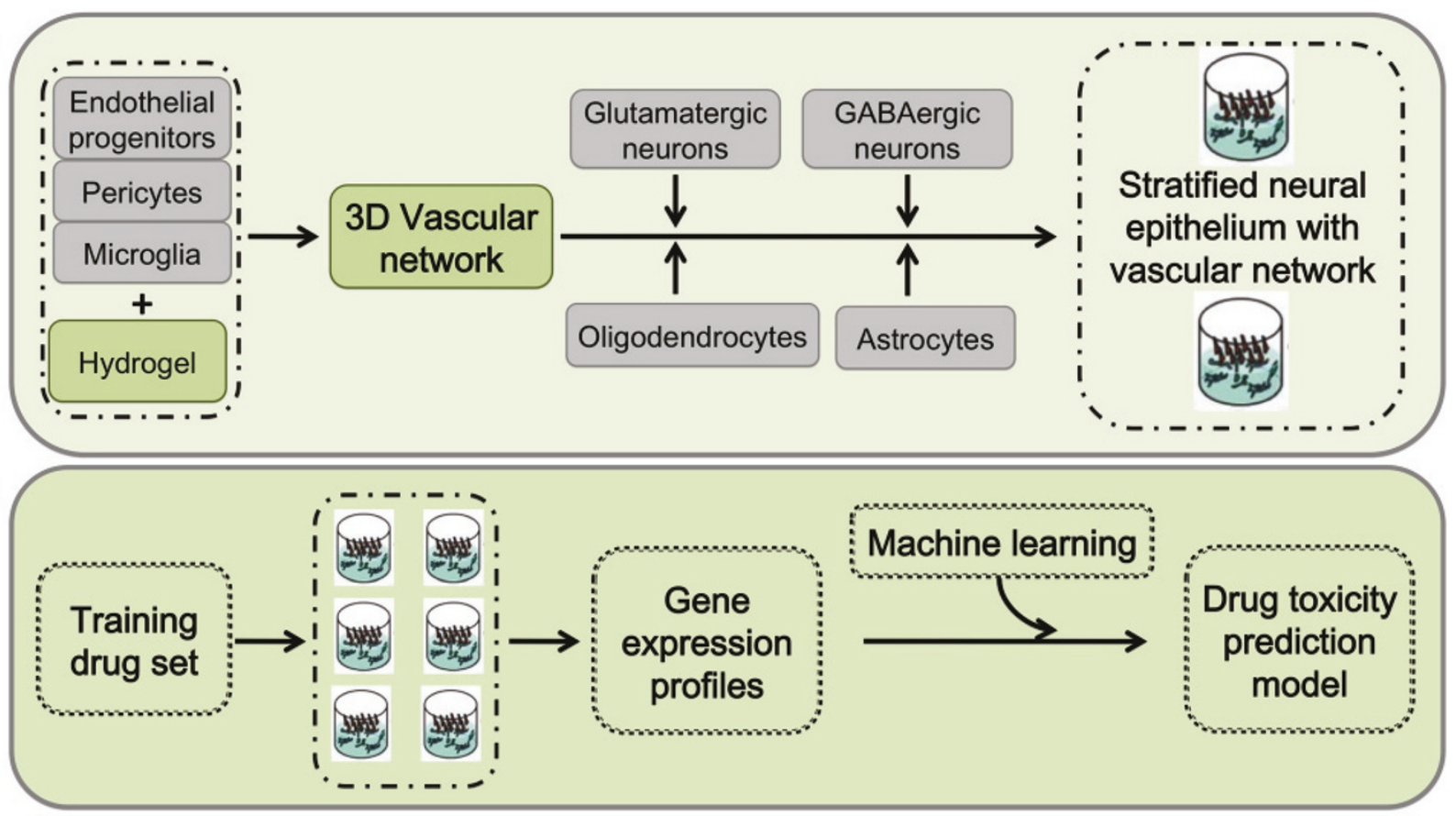

(c)

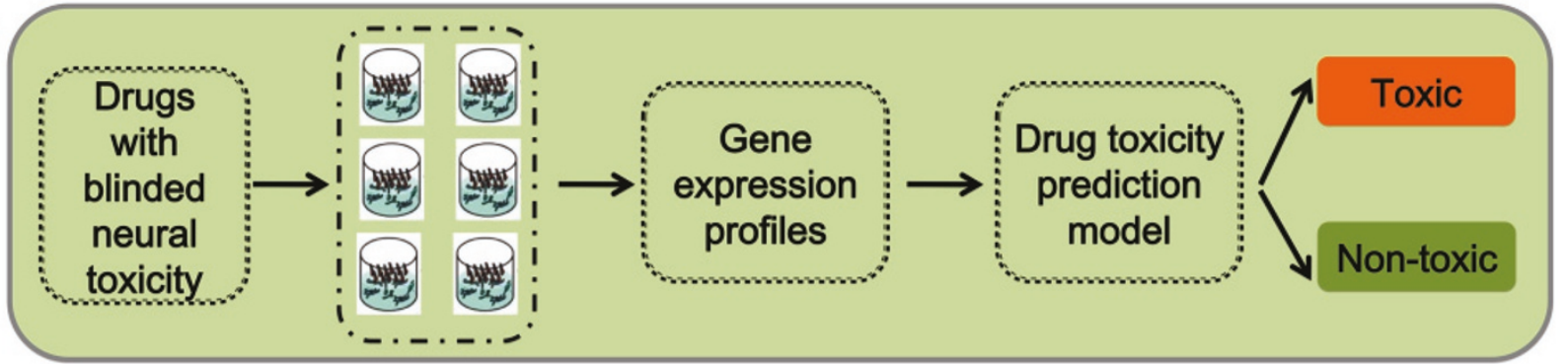

Figure 1. Platform set-up diagram. (a) Neural and glial progenitor cells are assembled on a three-dimensional (3D) vascular network formed by endothelial cells, pericytes, and microglia in poly(ethylene glycol) hydrogel to promote the formation of stratified neural epithelium with a vascular network. (b) The neural vascular assembly from (a) will be exposed to a training drug set. The gene expression profiles from the training set will be used to establish a drug toxicity prediction model using a machine learning algorithm. (c) The model established in (b) can be used to predict the toxicity of an unknown chemical.

large, defined batches, cryopreserve them, and later combine them into three-dimensional hydrogel assemblies, allowing those assemblies to interact and further mature for a more limited time during drug exposure.

\section{Platform readout}

Optimized screen readouts and machine learning tools are also important components of this platform. Our basic premise is that toxicants change the basic physiology of cells, and that these changes directly or indirectly cause changes in gene expression profiles that can, in turn, be used to classify specific classes of toxicants. The three-dimensional neural/glial/vascular assemblies, which initially consist of seven cell types, are complex; with further maturation, additional cell types or subtypes may also emerge. Because the specific targets of a novel toxic agent will be unknown and could be as diverse as the ensemble of molecules contained in these assemblies, readouts must reflect this complexity and have a substantial dynamic range, as minor alterations in the assemblies' cellular subcompartments may reflect relevant in vivo toxicity.

Importantly, the recent dramatic fall in the cost of high-throughput sequencing makes a readout based on expression profiling very desirable for drug screening purposes, as RNA-Seq allows the monitoring of complex samples with an excellent dynamic range and at a reasonable price per sample. This desirability of using gene expression profiling to better understand toxic responses is shown in recent reports using ES cell-based and other cellular models [30-33].

The platform's final component, a machine learning algorithm, uses the gene expression profiles of cells exposed to known developmental neural toxins to predict 


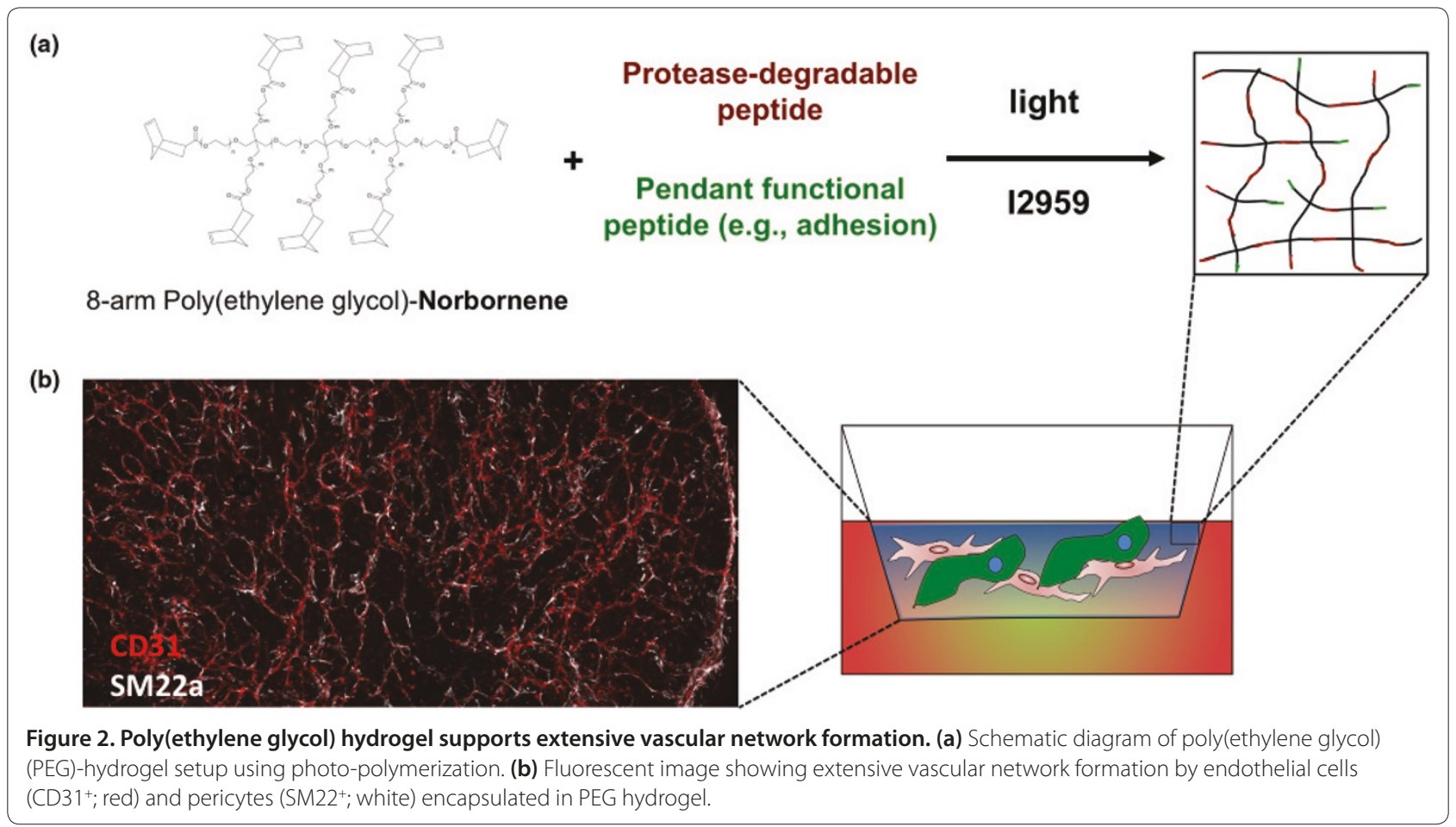

the neural toxicity of chemicals without previous toxicity information (Figure 1b,c).

\section{Conclusion}

In short, we combine the developmental potential of human pluripotent stem cells, the modular nature of the tunable hydrogels, and the discriminatory power of machine learning tools to create a highly sensitive model suitable for large-scale predictive developmental toxicology screens (Figure 1). This platform, and other $\mathrm{NIH}$ Microphysiological Systems, should provide a better understanding of chemical impacts on human health.

\section{Abbreviations}

ES, embryonic stem; iPS, induced pluripotent stem; NIH, National Institutes of Health.

\section{Competing interests}

JAT is a founder, stockowner, consultant and board member of Cellular Dynamics International (CDI), and serves as scientific advisor to and has financial interests in Tactics II Stem Cell Ventures. The remaining authors declare that they have no competing interests.

\section{Acknowledgements}

This work, and the publication costs of this article, was funded by $\mathrm{NIH}$ grant 1UH2TR000506-01 (to JAT).

\section{Declarations}

Publication of this supplement has not been supported by sponsorship. Articles have undergone the journal's standard review process. The Editors declare that they have no competing interests.

This article has been published as part of Stem Cell Research \& Therapy Volume 4 Supplement 1, 2013: Stem cells on bioengineered microphysiological platforms for disease modeling and drug testing. The full contents of the supplement are available online at http://www.stemcellres.com/supplements/4/S1.

\section{Author details}

'Morgridge Institute for Research, 330 N Orchard Street, Madison, WI 53715, USA. ${ }^{2}$ Department of Biomedical Engineering, College of Engineering, University of Wisconsin-Madison, 1415 Engineering Drive, Madison, WI 53706, USA. ${ }^{3}$ Department of Biostatistics and Medical Informatics, University of Wisconsin-Madison, K6/446 CSC, 600 Highland Avenue, Madison, WI 53792-4675, USA. ${ }^{4}$ Department of Orthopedics and Rehabilitation, School of Medicine and Public Health, University of Wisconsin-Madison, 1685 Highland Avenue, Madison WI 53705, USA. 5 Department of Cell \& Regenerative Biology, School of Medicine and Public Health, University of Wisconsin-Madison, Rm 327 Services Memorial Institute, 1300 University Ave, Madison, WI 53706, USA. ${ }^{6}$ Department of Molecular, Cellular \& Developmental Biology, University of California, Santa Barbara, Life Sciences \& Technology Building, Room 3308, Santa Barbara, CA 93106, USA.

Published: 20 December 2013

\section{References}

1. Morford LL, Henck JW, Breslin WJ, DeSesso JM: Hazard identification and predictability of children's health risk from animal data. Environ Health Perspect 2004, 112:266-271.

2. Collins FS, Gray GM, Bucher JR: Toxicology. Transforming environmental health protection. Science 2008, 319:906-907.

3. Hartung T: Toxicology for the twenty-first century. Nature 2009, 460:208-212

4. Hartung T, Rovida C: Chemical regulators have overreached. Nature 2009, 460:1080-1081.

5. US Environmental Protection Agency: Chemical Hazard Data Availability Study, Washington, DC: EPA Office of Pollution Prevention and Toxics; 1998.

6. Krewski D, Andersen ME, Mantus E, Zeise L: Toxicity testing in the 21st century: implications for human health risk assessment. Risk Anal 2009, 29:474-479.

7. Dix DJ, Houck KA, Martin MT, Richard AM, Setzer RW, Kavlock RJ: The ToxCast program for prioritizing toxicity testing of environmental chemicals. Toxicol Sci 2007, 95:5-12.

8. Committee on Toxicity Testing and Assessment of Environmental Agents NRC: Toxicity Testing for Assessment of Environmental Agents: Interim Report. Washington, DC: The National Academies Press; 2006.

9. Homburger F, Chaube S, Eppenberger M, Bogdonoff PD, Nixon CW: 
Susceptibility of certain inbred strains of hamsters to teratogenic effects of thalidomide. Toxicol Appl Pharmacol 1965, 7:686-693.

10. Adams J, Barone S, Jr, LaMantia A, Philen R, Rice DC, Spear L, Susser E: Workshop to identify critical windows of exposure for children's health: neurobehavioral work group summary. Environ Health Perspect 2000, 108(Suppl 3):535-544.

11. Moors M, Rockel TD, Abel J, Cline JE, Gassmann K, Schreiber T, Schuwald J, Weinmann N, Fritsche E: Human neurospheres as three-dimensional cellular systems for developmental neurotoxicity testing. Environ Health Perspect 2009, 117:1131-1138.

12. Thomson JA, Itskovitz-Eldor J, Shapiro SS, Waknitz MA, Swiergiel JJ, Marshall VS, Jones JM: Embryonic stem cell lines derived from human blastocysts. Science 1998, 282:1145-1147.

13. Yu J, Vodyanik MA, Smuga-Otto K, Antosiewicz-Bourget J, Frane JL, Tian S, Nie J, Jonsdottir GA, Ruotti V, Stewart R, Slukvin II, Thomson JA: Induced pluripotent stem cell lines derived from human somatic cells. Science 2007, 318:1917-1920.

14. Takahashi K, Tanabe K, Ohnuki M, Narita M, Ichisaka T, Tomoda K, Yamanaka S: Induction of pluripotent stem cells from adult human fibroblasts by defined factors. Cell 2007, 131:861-872.

15. Bal-Price AK, Hogberg HT, Buzanska L, Lenas P, van Vliet E, Hartung T: In vitro developmental neurotoxicity (DNT) testing: relevant models and endpoints. Neurotoxicology 2010, 31:545-554.

16. Breier JM, Gassmann K, Kayser R, Stegeman H, De Groot D, Fritsche E, Shafer TJ: Neural progenitor cells as models for high-throughput screens of developmental neurotoxicity: state of the science. Neurotoxicol Teratol 2010, 32:4-15.

17. Colleoni S, Galli C, Gaspar JA, Meganathan K, Jagtap S, Hescheler J, Sachinidis A, Lazzari G: Development of a neural teratogenicity test based on human embryonic stem cells: response to retinoic acid exposure. Toxicol Sci 2011 , 124:370-377.

18. Talens-Visconti R, Sanchez-Vera I, Kostic J, Perez-Arago MA, Erceg S, Stojkovic $M$, Guerri C: Neural differentiation from human embryonic stem cells as a tool to study early brain development and the neuroteratogenic effects of ethanol. Stem Cells Dev 2011, 20:327-339.

19. Thomson JA, Marshall VS, Trojanowski JQ: Neural differentiation of rhesus embryonic stem cells. APMIS 1998, 106:149-156; discussion 156-157.

20. Eiraku M, Watanabe K, Matsuo-Takasaki M, Kawada M, Yonemura S, Matsumura M, Wataya T, Nishiyama A, Muguruma K, Sasai Y: Self-organized formation of polarized cortical tissues from ESCs and its active manipulation by extrinsic signals. Cell Stem Cell 2008, 3:519-532.

21. Burdick JA, Murphy WL: Moving from static to dynamic complexity in hydrogel design. Nat Commun 2012, 3:1269.

22. Jongpaiboonkit L, King WJ, Lyons GE, Paguirigan AL, Warrick JW, Beebe DJ, Murphy WL: An adaptable hydrogel array format for 3-dimensional cell culture and analysis. Biomaterials 2008, 29:3346-3356.
23. Jongpaiboonkit L, King WJ, Murphy WL: Screening for 3D environments that support human mesenchymal stem cell viability using hydrogel arrays. Tissue Eng Part A 2009, 15:343-353.

24. Fairbanks BD, Schwartz MP, Halevi AE, Nuttelman CR, Bowman CN, Anseth KS: $A$ versatile synthetic extracellular matrix mimic via thiol-norbornene photopolymerization. Adv Mater 2009, 21:5005-5010.

25. Vodyanik MA, Bork JA, Thomson JA, Slukvin, II: Human embryonic stem cell-derived $\mathrm{CD}_{34}{ }^{+}$cells: efficient production in the coculture with OP9 stromal cells and analysis of lymphohematopoietic potential. Blood 2005, 105:617-626.

26. Kaufman DS, Lewis RL, Hanson ET, Auerbach R, Plendl J, Thomson JA: Functional endothelial cells derived from rhesus monkey embryonic stem cells. Blood 2004, 103:1325-1332.

27. Zhang SC, Wernig M, Duncan ID, Brustle O, Thomson JA: In vitro differentiation of transplantable neural precursors from human embryonic stem cells. Nat Biotechnol 2001, 19:1129-1133.

28. Hu BY, Du ZW, Zhang SC: Differentiation of human oligodendrocytes from pluripotent stem cells. Nat Protoc 2009, 4:1614-1622.

29. Krencik R, Weick JP, Liu Y, Zhang ZJ, Zhang SC: Specification of transplantable astroglial subtypes from human pluripotent stem cells. Nat Biotechnol 2011, 29:528-534

30. Kultima K, Nystrom AM, Scholz B, Gustafson AL, Dencker L, Stigson M: Valproic acid teratogenicity: a toxicogenomics approach. Environ Health Perspect 2004, 112:1225-1235

31. Robinson JF, Yu X, Moreira EG, Hong S, Faustman EM: Arsenic- and cadmiuminduced toxicogenomic response in mouse embryos undergoing neurulation. Toxicol Appl Pharmacol 2011, 250:117-129.

32. Suzuki N, Ando S, Sumida K, Horie N, Saito K: Analysis of altered gene expression specific to embryotoxic chemical treatment during embryonic stem cell differentiation into myocardiac and neural cells. J Toxicol Sci 2011 36:569-585.

33. Theunissen PT, Robinson JF, Pennings $J \mathrm{~L}$, de Jong E, Claessen SM, Kleinjans JC, Piersma AH: Transcriptomic concentration-response evaluation of valproic acid, cyproconazole and hexaconazole in the neural embryonic stem cell test (ESTn). Toxicol Sci 2012, 125:430-438

doi:10.1186/scrt373

Cite this article as: Hou Z, et al:: A human pluripotent stem cell platform for assessing developmental neural toxicity screening. Stem Cell Research \& Therapy 2013, 4(Suppl 1):S12 